\title{
Cost-utility of medication withdrawal in older fallers: results from the improving medication prescribing to reduce risk of FALLs (IMPROveFALL) trial
}

Suzanne Polinder ${ }^{1 *}$, Nicole D. A. Boyé ${ }^{2,3}$, Francesco U. S. Mattace-Raso ${ }^{2}$, Nathalie Van der Velde², Klaas A. Hartholt ${ }^{2,3}$, Oscar J. De Vries ${ }^{5}$, Paul Lips ${ }^{5}$, Tischa J. M. Van der Cammen², Peter Patka ${ }^{4}$, Ed F. Van Beeck Esther M. M. Van Lieshout ${ }^{3}$ and the IMPROveFALL trial collaborators

\begin{abstract}
Background: The use of Fall-Risk-Increasing-Drugs (FRIDs) has been associated with increased risk of falls and associated injuries. This study investigates the effect of withdrawal of FRIDs versus 'care as usual' on health-related quality of life (HRQoL), costs, and cost-utility in community-dwelling older fallers.

Methods: In a prospective multicenter randomized controlled trial FRIDs assessment combined with FRIDs-withdrawal or modification was compared with 'care as usual' in older persons, who visited the emergency department after experiencing a fall. For the calculation of costs the direct medical costs (intramural and extramural) and indirect costs (travel costs) were collected for a 12 month period. HRQoL was measured at baseline and at 12 months follow-up using the EuroQol-5D and Short Form-12 version 2. The change in EuroQol-5D and Short Form-12 scores over 12 months follow-up within the control and intervention groups was compared using the Wilcoxon Signed Rank test for continuous variables and the McNemar test for dichotomous variables. The change in scores between the control and intervention groups were compared using a two-way analysis of variance.
\end{abstract}

Results: We included 612 older persons who visited an emergency department because of a fall. The mean cost of the FRIDs intervention was $€ 120$ per patient. The total fall-related healthcare costs (without the intervention costs) did not differ significantly between the intervention group and the control group (€2204 versus $€ 2285$ ). However, the withdrawal of FRIDs reduced medication costs with a mean of $€ 38$ per participant. Furthermore, the control group had a greater decline in EuroQol-5D utility score during the 12-months follow-up than the intervention group $(p=0.02)$. The change in the Short Form-12 Physical Component Summary and Mental Component Summary scores did not differ significantly between the two groups.

Conclusions: Withdrawal of FRID's in older persons who visited an emergency department due to a fall, did not lead to reduction of total health-care costs. However, the withdrawal of FRIDs reduced medication costs with a mean of €38 per participant in combination with less decline in HRQoL is an important result.

Trial registration: The trial is registered in the Netherlands Trial Register (NTR1593 - October $1^{\text {st }}$ 2008).

Keywords: Quality of life, Medication withdrawal, Cost utility, Older persons, Falls

\footnotetext{
*Correspondence: s.polinder@erasmusmc.nl

'Department of Public Health, Erasmus MC, University Medical Center

Rotterdam, PO Box 20403000, CA, Rotterdam, The Netherlands

Full list of author information is available at the end of the article
} 


\section{Background}

Fall incidents represent an increasing burden on health care systems in aging societies worldwide. Falls affect a large proportion of persons aged 65 years and older and are associated with high mortality and morbidity, leading to great personal suffering, represented in loss of quality of life and high costs [1-5]. Older fallers cause high numbers of Emergency Department (ED) visits and hospital admissions [6, 7]. In 2000, the fall-related medical costs in the population aged 65 years and older in the United States amounted to US\$19 billion for nonfatal injuries and US\$200 million for fatal injuries [8]. Between 2003 and 2007 the average annual cost for fallrelated injuries in the Netherlands was US\$640 million (€470 million) [9]. The overall cost per fall was US $\$ 10,540$ (€7800), mainly caused by direct medical costs [10].

In order to reduce the prevalence of falls, potentially avoidable risk factors have been well documented [11-13], and there has been a substantial number of falls prevention trials [5, 14-22]. However, past variations in outcome definitions and measures of falls prevention trials have hindered comparative research and meta-analysis, and thus the Prevention of Falls Network Europe (ProFaNE) established a common set of outcome definitions and measures for use in trials. These include costs, healthrelated quality of life (HRQoL) outcomes, and a follow-up duration of 12 months [23]. But so far only few fallprevention trials have documented quality of life outcomes [18, 24-27] and the HRQoL as recommended by ProFaNE has been reported in only one of them [18]. Moreover, economic evaluations on falls prevention are scarce. However, evidence from reviews targeting economic evaluation studies of single factor falls prevention interventions like exercise programs $[28,29]$ and multifactorial falls prevention interventions [30] is promising.

The use of FRIDs has been associated with increased risk of falls and associated injuries [31-35]. The withdrawal of FRIDs has been shown to be safely possible and to generate significant cost savings in some patients [14, 36, 37], but the cost-utility of this approach has not been reported yet. The present study investigated costs, the effect on HRQoL, and the cost-utility of a structured medication assessment including withdrawal of FRIDs versus 'care as usual' in community-dwelling older men and women, who visited the ED after experiencing a fall [38].

\section{Methods}

\section{Study design}

The IMPROveFALL study is a multicenter randomized controlled trial in the Netherlands. Eligible patients were randomized to one of the treatment arms using a web-based randomization program. Variable block randomization was accomplished via a trial website. Allocation was at random and concealed. The patients were randomized to the intervention group or 'care as usual'. It was not possible to blind the geriatrician and patients for the allocation of the study group. The study was performed in accordance with the Declaration of Helsinki and all participants gave written informed consent. The local Medical Research Ethics Committees in the six participating hospitals approved the study protocol. A detailed description of the study protocol can be found elsewhere [38].

\section{Study population}

Patients meeting the following inclusion criteria were eligible for enrolment: age 65 years or older, visited the ED due to a fall, use of one or more FRIDs [32, 33, 35, 38], Mini-Mental State Examination (MMSE) score of at least 21 out of 30 points [39], ability to walk independently, community dwelling, and provision of written informed consent by the patient. Participating hospitals included two academic and four regional hospitals in the Netherlands. Enrolment started in October 2008 and was completed in October 2011. The follow-up period was 12 months.

All persons visiting the ED because of a fall received care as usual for their injuries. Following the ED visit, patients were contacted by telephone. Subsequently, eligible and interested potential study participants received an appointment for the research outpatient clinic. The visits to the research outpatient clinic took place within two months after the fall-related ED visit. If the patient met all eligibility criteria, the patient was asked to sign the Informed Consent form. During the visit to the research outpatient clinic, a fall-related assessment was performed by the research physician.

\section{Intervention}

All participants received a structured medication assessment. The intervention group consisted of a systematic FRIDs assessment combined with FRIDs withdrawal or modification, if safely possible. A complete list of FRIDs is presented in Appendix A. For each drug, the research physician assessed whether the initial indication still existed. Proposed changes in medication were discussed with a senior geriatrician, and if necessary with the prescribing physician. A research nurse offered counselling, evaluated possible negative effects via a standardized telephone follow-up, and discussed any problems regarding the drug modification with the research physician and geriatrician.

\section{Definition fall incident}

A fall was defined as coming to rest unintentionally on the ground or a lower level with or without losing 
consciousness, but not induced by acute medical conditions, e.g., stroke, or exogenous factors such as a traffic accident [40]. All participants received a Falls Calendar for reporting falls during a one-year follow-up period. Falls were recorded weekly on the Fall Calendars, which had to be returned every three months. Follow-up started two weeks after completed intervention or two weeks after initial research clinic visit when no intervention was performed.

\section{Costs}

The total direct and indirect costs of both FRIDs withdrawal and 'care as usual' were measured. Costs were calculated by multiplying the volumes of healthcare use with the corresponding unit prices (Table 1). Direct healthcare costs included the costs of the FRIDs assessment and modification, drug consumption (i.e., the cost of substitution drugs), and fall-related healthcare consumption during one year of follow-up (e.g., outpatient visits, hospital admissions, General Practitioner consultations, home care, nursing home care). Indirect costs included patient travel costs. For the intervention (systematic fall-related drugs assessment) the full cost price was calculated and for the other healthcare costs standard Dutch cost prices were used as published earlier by Hakkaart-van Roijen et al. [41]. Costs of medication use were recorded in the study, and unit costs were determined with information from the National Dutch Formulary [42]. Healthcare consumption, both fall and non-fall related, and patient costs were recorded from the three-monthly questionnaires for healthcare consumption

Table 1 List of costs

\begin{tabular}{|c|c|c|c|}
\hline Cost categories & Parameter & $\begin{array}{l}\text { Source of } \\
\text { consumption data }\end{array}$ & $\begin{array}{l}\text { Cost price } \\
(€, 2009)\end{array}$ \\
\hline Intervention costs & * & Study registry & Variable \\
\hline Medication costs & DDD & Study registry & Variable \\
\hline Hospital stay costs & Day & Hospital registry & 457 \\
\hline $\begin{array}{l}\text { Emergency Department } \\
\text { costs }\end{array}$ & Visit & Hospital registry & 151 \\
\hline General Practitioner costs & Consultation & Questionnaire & 28 \\
\hline Specialist consult costs & Consultation & Hospital registry & 72 \\
\hline Home care costs & Per hour & Questionnaire & 35 \\
\hline Physical therapy costs & Visit & Questionnaire & 36 \\
\hline Nursing home costs & Day & Questionnaire & 238 \\
\hline $\begin{array}{l}\text { Intermediate care facility } \\
\text { costs }\end{array}$ & Day & Questionnaire & 90 \\
\hline $\begin{array}{l}\text { Rehabilitation center } \\
\text { costs }\end{array}$ & Day & Questionnaire & 340 \\
\hline Patient costs (travel costs) & Per kilometer & Questionnaire & Variable** \\
\hline
\end{tabular}

$D D D$ Defined Daily Dose, GP General Practitioner

*Geratric consultation $(€ 72)$ + routine blood test $(€ 20)$ + extra consults $(€ 72)$

**Private motor vehicle/public transportation/taxi and patient costs. Furthermore we collected data from the participants' General Practitioner, by sending a questionnaire on healthcare use.

The number of injuries prevented was calculated with data recorded in the three-monthly questionnaire, supplemented with epidemiological data on falls and injury risks. These were supplemented with data on healthcare costs of injury from previous research [10].

\section{Health-related quality of life}

During the baseline assessment and during the followup visit at 12 months follow-up, all participants were asked to complete the patient outcome questionnaire (see Additional file 1), under supervision of the clinical investigator or research nurse. Based upon the recommendations of ProFaNE [23], HRQoL was measured using the Dutch versions of the EuroQol-5D (EQ-5D) [43] and the Short Form-12 (SF-12) version 2 [44]. The EQ-5D is recommended for the assessment of HRQoL in trauma patients, especially for economic assessments [45]. The EQ-5D instrument covers five health domains (mobility, self-care, usual activities, pain/discomfort, and anxiety/depression). Each dimension has three levels; no problem, moderate problem, or severe problem. In addition, a scoring algorithm based on empiric valuations from the United Kingdom general population and subsequent statistical modeling is available by which the health status descriptions can be expressed into a utility score [46]. This utility score ranges from 1 for full health to 0 for death, and can be interpreted as a judgment on the relative desirability of a health status compared with perfect health. The EQ-5D is a validated and extensively used general health questionnaire to measure quality of life [43]. The SF-12 contains eight domains measuring physical and mental health outcomes; physical functioning, role physical, bodily pain, general health, vitality, social functioning, role emotional, and mental health. Data from all eight domains are used to construct the physical and mental component summary measures (PCS and MCS) [44].

\section{Cost-utility analysis}

The long-term effectiveness of the interventions was expressed in terms of the cumulative number of life years and quality-adjusted life years (QALYs) gained. The QALY combines morbidity and mortality into a single number. QALYs were calculated by weighting life years for the quality of life using the EQ-5D utility score over 12 months (12 months follow-up minus baseline). The gain in QALY is equal to the difference of QALY outcomes between the two study arms.

Finally, the cost per QALY gained was calculated as the ratio of total intervention costs minus savings in fallrelated healthcare costs compared with control divided 
by the cumulative QALYs gained compared with control. All analyses were performed in accordance with Dutch guidelines for economic evaluations [47].

\section{Statistical analyses}

All analyses were performed using the Statistical Package of the Social Sciences (SPSS version 17.0, Chicago, Ill.) and a $p$-value $<0.05$ was considered statistically significant. Missing data were not imputed. Baseline characteristics were compared using Student $t$-test analyses for continuous variables and chi-squared analyses for dichotomous variables. The change in EQ-5D utility score and SF-12 PCS and MCS scores over 12 months (i.e., after 12 months follow-up minus baseline data) within the control and intervention groups were compared using the Wilcoxon Signed Rank test for continuous variables and the McNemar test for dichotomous variables. The change in scores between the control and intervention groups were compared using a two-way analysis of variance (ANOVA). Analyses of the individual health domains of the EQ-5D and SF-12 were also performed. Secondary analyses were performed, comparing the HRQoL scores of the participants with and without a fall during follow-up.

\section{Results}

In total, $7081 \mathrm{ED}$ visitors were screened for inclusion in the study, of which 3294 were not eligible, 1954 refused to participate, 279 persons died before contact, 938 patients were failed to contact within 2 months, and of 4 patients data was lost. Subsequently, 612 participants were randomized in the IMPROveFALL study (Fig. 1).

This randomization resulted in 319 participants to the intervention group and 293 participants allocated to the control group. In total 271 participants from the control group and 308 participants from the intervention group had complete intramural and extramural cost information. Finally, 265 and 287 participants respectively from the control and intervention group completed quality of life assessments at baseline and at 12 months follow-up (Fig. 1). The mean age was 76 years and $62 \%$ of the study population was female. No significant differences in baseline characteristics were found between the control and intervention group (Table 2).

The number of participants in the control group and intervention group experiencing a fall or recurrent fall during the one-year follow-up did not differ significantly (34. \% versus $37 \% ; p=0.33$ ) [48].

The mean number of FRIDs used at baseline was four. In $40 \%$ of all FRIDs an intervention was deemed not possible or not necessary. Of all attempted FRIDwithdrawals $35 \%$ failed, either due to non-compliance or due to a return of the primary indication for which the drug had initially been prescribed. More detailed specifications on the interventions according to FRID categories and specific drug types, and details on compliance to attempted interventions has been published before [48].

\section{Intervention costs}

The mean cost of the FRIDs intervention was $€ 120$ per patient, which included the initial research clinic assessment $(€ 72)$, routine blood tests $(€ 20)$ and when necessary (78 patients one or more checks) additional checks/ assessments $(€ 72)$.

\section{Cost savings}

The mean costs saved with medication withdrawal, dose reduction and drug substitution was $€ 38$ per participant for the intervention group.

For all other intramural and extramural care no significant differences in costs were found, except for general practitioner visits (Table 3). However, for all but two health care items the costs were lower for the intervention group. Rehabilitation caused relatively the highest costs, with much higher costs for the intervention group than for the control group ( $€ 708$ versus $€ 229$; NS). In total 15 patients received rehabilitation care (10 in the intervention arm) varying from 6 to 120 days stay, of which the 6 patients with the longest stay in rehabilitation were all in the intervention arm. Comparing intermediate care facility and nursing home costs between both groups, it is striking that the numbers of patients receiving either type of care were similar, however, the long stayers for both health care facilities were in the control group.

The intramural and extramural fall-related healthcare costs (without the intervention costs of €120) did not differ significantly between the intervention group compared with the control group ( $€ 2204$ versus $€ 2285$; NS).

\section{Health-related quality of life}

Nine participants in the control and 23 in the intervention group declined or were unable to complete the EQ5D questionnaires after 12-months follow-up. Additional 5 and 2 participants in the control and intervention group, respectively, had incomplete SF-12 questionnaires after 12-months follow-up.

The baseline and follow-up HRQoL scores of the control and intervention group are shown in Table 4. The control group had a greater decline in EQ-5D utility score during the 12-months follow-up than the intervention group, $(p=0.02)$. The decline in the SF-12 PCS and MCS score did not differ significantly between the two groups $(p=0.08$ and $p=0.90)$. The problems in the EQ-5D domains of the control and intervention group reported at baseline and at follow-up are shown in Fig. 2. Control patients reported significantly more problems 


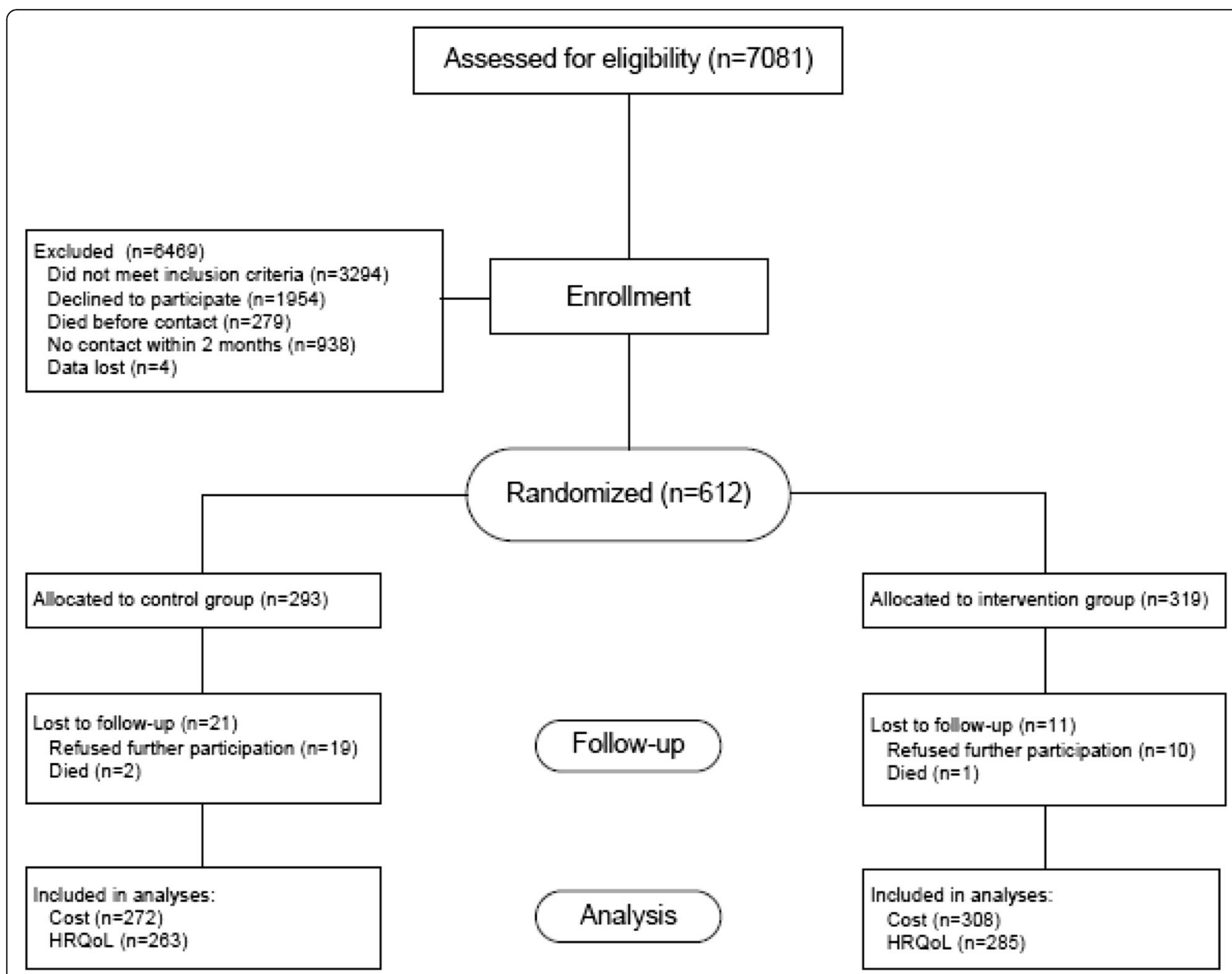

Fig. 1 Flowchart of study participants. *Of the participants who died during follow-up, most were included in the analyses, except for two in the control and one in the intervention group. ${ }^{*}$ Nine and 23 participants in the control and intervention group declined or were unable to complete EQ-5D questionnaires after 12-months follow-up

with mobility (increase of $9 \% ; p=0.01$ ) at 12-months follow-up, which mainly explains the decline in HRQoL in the control group.

The overall mean baseline EQ-5D utility score of participants with and without a fall during follow-up was $0.69 \pm 0.27$ and $0.80 \pm 0.21$, respectively $(p<0.01)$. The overall mean baseline SF-12 PCS scores of those with and without a fall during follow-up were $44.4 \pm 9.9$, and $46.6 \pm 9.6, p=0.01$. The overall mean baseline SF-12 MCS scores of those with and without a fall during follow-up were $53.2 \pm 10.0$, and $53.3 \pm 9.0, p=0.87$. Thus, the participants who experienced further falls during follow-up had significantly lower EQ-5D and SF-12 PCS scores at baseline. A secondary analysis was performed of the decline in HRQoL in the participants of the control and intervention group with and without a fall during follow-up (Table 5). In the participants with a fall during follow-up, the change in quality of life did not differ significantly between both groups. In the participants without a fall during follow-up, the control group had a greater decline in the SF-12 PCS score $(p=0.01)$ than the intervention group.

\section{Cost-utility}

The mean QALY difference between both groups was 0.05 QALY (gained by the intervention group) over the trial period. For the total fall-related healthcare costs (with and without the intervention costs of $€ 120$ ), no significantly differences between both study groups could be detected. Therefore, no incremental cost-utility ratio was calculated.

\section{Discussion}

This is the first cost-utility analysis comparing a structured medication assessment including withdrawal of FRIDs versus 'care as usual' in community-dwelling 
Table 2 Baseline characteristics of the control and intervention group

\begin{tabular}{|c|c|c|}
\hline & $\begin{array}{l}\text { Control } \\
n=293\end{array}$ & $\begin{array}{l}\text { Intervention } \\
n=319\end{array}$ \\
\hline \multicolumn{3}{|l|}{ Demographics } \\
\hline Age (year) & $76.4 \pm 6.6$ & $76.5 \pm 7.2$ \\
\hline Female gender & $182(62)$ & $198(62)$ \\
\hline MMSE & $27.0 \pm 2.4$ & $27.0 \pm 2.3$ \\
\hline $\mathrm{BMI}\left(\mathrm{m}^{2} / \mathrm{kg}\right)$ & $27.6 \pm 4.7$ & $27.6 \pm 4.6$ \\
\hline \multicolumn{3}{|l|}{ Fall risk factors } \\
\hline Charlson Comorbidity Index & $1.9 \pm 1.6$ & $1.9 \pm 1.6$ \\
\hline Number of drugs & $6.4 \pm 3.3$ & $6.3 \pm 3.3$ \\
\hline Number of FRIDs & $3.9 \pm 2.0$ & $3.9 \pm 2.1$ \\
\hline History of recurrent falls & $128(44)$ & $148(46)$ \\
\hline Smoking & $37(13)$ & $34(11)$ \\
\hline Alcohol intake ( $\geq 3$ units/day) & $33(11)$ & $34(11)$ \\
\hline \multicolumn{3}{|l|}{ Functional status } \\
\hline Home care & $69(24)$ & $82(26)$ \\
\hline Activities of Daily Living & $0.80 \pm 4.5$ & $0.80 \pm 3.3$ \\
\hline Instrumental Activities of Daily Living & $1.39 \pm 5.4$ & $1.37 \pm 4.0$ \\
\hline
\end{tabular}

Continuous data are shown as mean values \pm standard deviation, categorical data as number with percentage

MMSE Mini-Mental State Examination, BMI Body Mass Index, FRID Fall-Risk Increasing Drugs

Table 3 Mean costs per patient of the control and intervention group during 12 months follow-up

\begin{tabular}{llll}
\hline Cost categories & $\begin{array}{l}\text { Control } \\
(n=272)\end{array}$ & $\begin{array}{l}\text { Intervention } \\
(n=308)\end{array}$ & p-value \\
\hline Intervention costs & - & $120^{\dagger}$ & $*$ \\
General Practitioner consult costs & 29 & 20 & $*$ \\
Specialist consult costs & 51 & 40 & \\
Emergency Department costs & 12 & 10 & \\
Hospital stay costs & 360 & 383 & \\
Home care costs & 662 & 630 & \\
Physical therapy costs & 290 & 218 & \\
Intermediate care facility costs & 220 & 74 & \\
Nursing home costs & 424 & 156 & \\
Rehabilitation center costs & 229 & 708 & \\
Patient costs (travel costs) & 3 & 2 & \\
Change in medication costs & -3 & -38 & \\
Total costs & 2285 & 2324 & \\
\hline
\end{tabular}

Data are given as mean values in euro $(€){ }^{\dagger}$ Average ${ }^{*}<0.05$ \# The change in medication costs was reported, since the main aim of the intervention was to withdraw medication. The total costs of medication in general is related to the health state and comorbidity at start of the intervention and were highly driven by some outliers older fallers conform the PROFANE guideline. The savings in fall-related healthcare cost did not differ significantly between the control and intervention group. However, the control group reported a significantly greater decline in HRQoL during the 12-months followup as measured with the EQ-5D utility score than the intervention group.

Various studies have reported costs and costeffectiveness data regarding falls prevention trials with varying results. But these studies evaluated, in most cases, multifactorial interventions [30, 49-58]. One study reported on the cost-effectiveness of FRIDs withdrawal as a single intervention, and reported significant national cost savings [36]. In the current study, the savings in fall-related healthcare related costs in the intervention group did not differ significantly from usual care. This seems consistent with our findings that FRIDs-withdrawal was not effective in reducing falls [48]. There are several possible explanations for this lack of fall incidence reduction. In short, since in the last decade falls prevention guidelines have been incorporated into usual care, this may well have blunted the effect of the current intervention. In addition, a large proportion of the participants was not compliant to the intervention, especially with respect to withdrawal of psychotropic drugs (FRIDs withdrawal failed for $48 \%$ [48]). Higher compliance rates might have led to reduced falls and lower related healthcare costs, and increased savings due to reduced medication costs (mean reduction of $€ 38$ per participant in this study). Furthermore, a less costly method of FRIDs withdrawal could be accomplished by having the GP perform the intervention. This approach has been shown to be successful, but would require an initial training programme for the GPs [59].

Until now, only one falls prevention trial reported HRQoL as recommended by ProFaNE. This multifactorial intervention trial reported no significant change in EQ-5D and SF-12 scores between the intervention and control group [18]. Four other trials used varying methods to measure HRQoL. Two found no difference in SF-36 score between the intervention and control group [24, 25]. Another multifactorial falls prevention trial, which used the 15D instrument, concluded that the intervention produced positive effects in some dimensions of HRQoL [27]. Still another trial used the World Health Organization Quality of Life instrument (WHOQoL) and measured higher quality of life in an exercise training intervention group of patients who had recently fallen [26].

Except for a structured medication assessment, including the withdrawal of FRIDs, both groups received identical care. Furthermore, withdrawal of certain commonly prescribed FRIDs such as benzodiazepines, antidepressants 
Table 4 Quality of life scores of the control and intervention group at baseline and 12 months follow-up, and the change over 12 months

\begin{tabular}{llllllll}
\hline & Group & $\mathrm{N}^{\dagger}$ & Baseline & Follow-up & $p$-values & Change $^{*}$ & $p$-values \\
\hline EQ-5D utility score & Control & 263 & $0.78 \pm 0.22$ & $0.74 \pm 0.25$ & 0.01 & $-0.04 \pm 0.22$ & 0.02 \\
& Intervention & 285 & $0.74 \pm 0.26$ & $0.75 \pm 0.26$ & 0.75 & $0.01 \pm 0.24$ \\
SF-12 PCS score & Control & 258 & $46.2 \pm 9.9$ & $42.2 \pm 11.6$ & $<0.01$ & $-3.9 \pm 8.5$ & 0.08 \\
& Intervention & 283 & $45.6 \pm 9.5$ & $43.0 \pm 10.7$ & $<0.01$ & $-2.6 \pm 8.5$ & $-0.7 \pm 9.7$ \\
SF-12 MCS score & Control & 258 & $53.2 \pm 9.0$ & $52.5 \pm 9.2$ & 0.28 & $-0.8 \pm 9.7$ & 0.90 \\
& Intervention & 283 & $53.3 \pm 9.5$ & $52.5 \pm 9.0$ & 0.20 & & - \\
\hline
\end{tabular}

Data are given as mean values \pm standard deviation

${ }^{\dagger} 9$ and 23 participants in the control and intervention group declined or were unable to complete EQ-5D questionnaires after 12-months follow-up, an additional

5 and 2 participants in the control and intervention group had incomplete SF-12 questionnaires after 12-months follow-up

*Wilcoxon Signed Rank test (comparing baseline and follow-up)

**Two-way ANOVA of the change over 12 months

and opiates [38], could have resulted in lower quality of life scores in the intervention group. Nevertheless, in this study the withdrawal of FRIDs did not lower the HRQoL. Remarkably, in the secondary analysis comparing the participants without a fall during follow-up, the intervention group had less decline in the SF-12 PCS score than the control group. The fact that the intervention did not lower the HRQoL and possibly even improved it, is on its own an important outcome. The participants who fell during follow-up had significantly lower EQ-5D and SF-12 PCS scores at baseline. This is in a group of communitydwelling older persons who all visited the ED due to a fall;

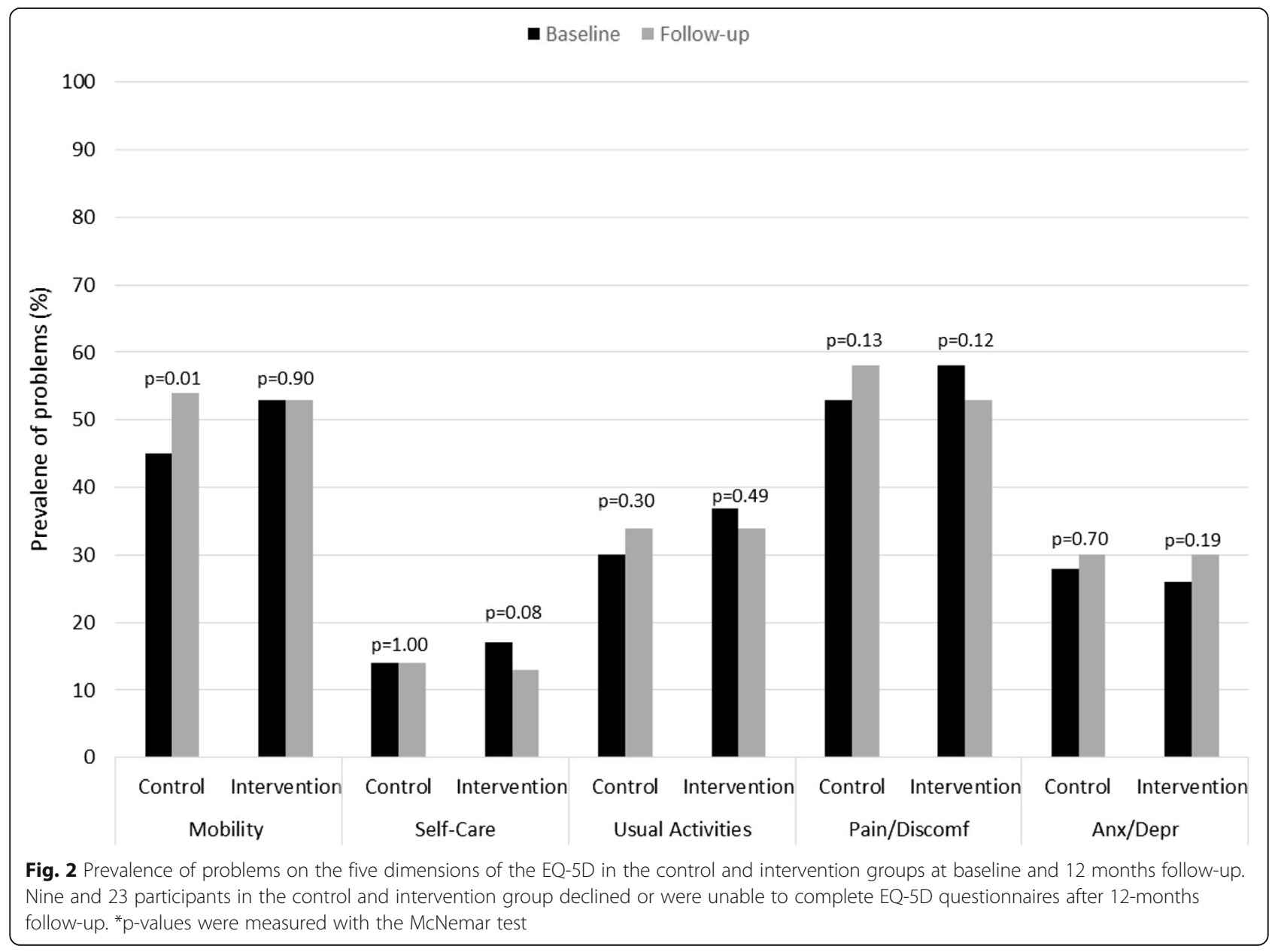


Table 5 Quality of life scores of the participants with and without a fall during follow-up

\begin{tabular}{|c|c|c|c|c|c|c|c|}
\hline Fall & Group & $\mathrm{N}$ & Baseline & Follow-up & $p$-values* & Change & $p$-values** \\
\hline \multirow[t]{2}{*}{ EQ-5D utility score } & Control & 87 & $0.71 \pm 0.25$ & $0.64 \pm 0.28$ & 0.01 & $-0.07 \pm 0.29$ & 0.13 \\
\hline & Intervention & 101 & $0.68 \pm 0.29$ & $0.67 \pm 0.28$ & 0.70 & $-0.01 \pm 0.27$ & \\
\hline \multirow[t]{2}{*}{ SF-12 PCS score } & Control & 88 & $44.0 \pm 10.4$ & $39.3 \pm 13.1$ & $<0.01$ & $-4.7 \pm 9.8$ & 0.72 \\
\hline & Intervention & 107 & $44.8 \pm 9.5$ & $40.7 \pm 11.2$ & $<0.01$ & $-4.2 \pm 10.2$ & \\
\hline \multirow[t]{2}{*}{ SF-12 MCS score } & Control & 88 & $53.6 \pm 9.1$ & $51.6 \pm 10.5$ & 0.14 & $-1.9 \pm 10.8$ & 0.56 \\
\hline & Intervention & 107 & $52.4 \pm 10.6$ & $51.7 \pm 9.2$ & 0.25 & $-1.0 \pm 11.1$ & \\
\hline No fall & Group & $\mathrm{N}$ & Baseline & Follow-up & $p$-values* & Change & $p$-values** \\
\hline \multirow[t]{2}{*}{ EQ-5D utility score } & Control & 169 & $0.81 \pm 0.19$ & $0.80 \pm 0.22$ & 0.27 & $-0.02 \pm 0.16$ & 0.08 \\
\hline & Intervention & 180 & $0.77 \pm 0.24$ & $0.80 \pm 0.23$ & 0.44 & $0.02 \pm 0.16$ & \\
\hline \multirow[t]{2}{*}{ SF-12 PCS score } & Control & 172 & $47.3 \pm 9.6$ & $43.9 \pm 10.4$ & $<0.01$ & $-3.5 \pm 7.8$ & 0.01 \\
\hline & Intervention & 178 & $46.1 \pm 9.6$ & $44.5 \pm 10.2$ & $<0.01$ & $-1.5 \pm 7.1$ & \\
\hline \multirow[t]{2}{*}{ SF-12 MCS score } & Control & 172 & $53.1 \pm 9.0$ & $53.0 \pm 8.5$ & 0.76 & $-0.1 \pm 9.2$ & 0.46 \\
\hline & Intervention & 178 & $53.9 \pm 8.8$ & $53.0 \pm 8.9$ & 0.40 & $-0.9 \pm 8.8$ & \\
\hline
\end{tabular}

$C$ control, I intervention. Data are given as mean values \pm standard deviation *Wilcoxon Signed Rank test

**Two-way ANOVA

those who fell during follow-up had lower quality of life scores ahead of the recurrent fall. This finding has not been reported before and can be used as a tool in further research and investigations to identify those older fallers most at risk of a further fall.

An important finding in this study was the lower baseline EQ-5D utility score in the intervention group compared to the control group, regardless of similar baseline characteristics including age, gender, and number of comorbidities. This cannot be a result of differences in reporting procedures, as the method and timing of HRQoL questionnaire completion were identical for the control and intervention groups. A possible explanation for the lower baseline EQ-5D utility score in the intervention group could be the presence of more severe injuries in the intervention group at baseline. However, the injuries sustained by the participants at baseline did not differ significantly between the two groups. Overall, $42 \%$ of participants sustained a fracture at baseline, $43 \%$ in the control group and $40 \%$ in the intervention group. Furthermore, $3 \%$ of participants in the control and in the intervention groups sustained a traumatic brain injury at baseline.

Some limitations should be taken into account when interpreting results of this study.

First, recruiting participants proved challenging, the recruitment-period lasted four years despite enrolling at six hospitals. Reasons for refusing to participate have been reported previously, i.e., mobility impairment and lack of transportation options [60]. Second, the dropout of 32 participants during the 12 months follow-up might be due to the selected study population, which had a high risk of falling. These participants had often mobility impairments and other multiple morbidity which may have resulted in a refusal to continue participating in the study and visit the outpatient research clinic after 12 months follow-up. Thus the most at-risk and frail participants may have been excluded from the analysis. More individuals were excluded from the intervention group because of poorer HRQoL (23 of the 32 dropouts) which may have influenced, at least in part, the better outcomes in the intervention group.

However, the randomization would have equally divided these patients across the intervention and control group. Third, the SF-12 has been evaluated for use in large group comparisons, this may not be justified for the secondary analyses comparing participants with and without a fall during follow-up [44]. Fourth, randomization did not seem to balance the groups on some important variables (e.g., rehabilitation, nursing home care), which can be attributed to the relatively small sample size of the study.

\section{Conclusions}

In the present study withdrawal of FRID's in older persons who visited an Emergency Department due to a fall, did not lead to reduction of total healthcare costs. The mean cost of the FRIDs intervention was $€ 120$ per patient, but this did not result in significant cost reductions in total healthcare costs. However, the withdrawal of FRIDs reduced medication costs with a mean of $€ 38$ per participant which in combination with less decline in HRQoL is an important result. 


\section{Additional file}

Additional file 1: Improvefall study patient questionnaire. Patients included in the Improvefall studie received a patient outcome questionnaire regarding medical history, quality of life and a fall risk profile. (PDF $536 \mathrm{~kb}$ )

\section{Abbreviations}

ED: Emergency department; EQ-5D: EuroQol-5D; FRIDs: Fall-risk-increasing-drugs; HRQOL: Health-related quality of life; IMPROveFALL: Improving medication prescribing to reduce risk of FALLs; MCS: Mental component summary score; MMSE: Mini-mental state examination; PCS: Physical component summary score ProFaNE: Prevention of falls network Europe; QALY: Quality-adjusted life year; SF-12: Short form-12; WHOQoL: World health organization quality of life instrument

\section{Acknowledgement}

\section{IMPROveFALL trial collaborators}

Erasmus MC, University Medical Center Rotterdam, Rotterdam: T.J.M. van der Cammen, P. Patka, E.F. Van Beeck, N. Van der Velde, E.M.M. Van Lieshout, S. Polinder, F.U.S. Mattace-Raso, K.A. Hartholt, N.D.A. Boyé, C.W.N. Looman. VU University Medical Center, Amsterdam: P. Lips, O.J. De Vries. Sint Franciscus Gasthuis, Rotterdam: A.J.H. Kerver.

IJsselland Hospital, Capelle aan den IJssel: M.M.M. Bruijninckx. Reinier de Graaf Groep, Delft: M.R. de Vries. Havenziekenhuis, Rotterdam: G. Ziere.

\section{Participating Dutch hospitals}

Erasmus MC, University Medical Center Rotterdam, P.O. Box 2040, 3000 CA Rotterdam; Franciscus Gasthuis, Kleiweg 5003045 PM Rotterdam; VU University Medical Center, P.O. Box 7057, 1007 MB Amsterdam; Harbour Hospital Rotterdam, Haringvliet 23011 TD, Rotterdam; IJsselland Hospital, P.O. Box 690, 2900 AR Capelle aan den IJssel; Reinier de Graaf Groep, P.O. Box 5011, 2600 GA Delft.

\section{Funding}

The study is funded by a grant from The Netherlands Organization for Health Research and Development (ZonMw), project number 170.885.607. The funding body has no role in study design, data collection and analysis, decision to publish, or preparation of the manuscript.

\section{Availability of data and materials}

Data supporting the findings is available upon request. Please contact the Principal Investigator of the study, Professor Francesco US Mattace-Raso (f.mattaceraso@erasmusmc.nl) for data availability.

\section{Authors' contributions}

$S P, N D A B$, and EMMVL drafted the manuscript, and all authors contributed substantially to its revision. NDAB, SP, EMMVL, and EFVB analysed and interpreted data. NVDV, EMMVL, KAH, PL, TJMVDC, PP, and EFVB designed the study, obtained funding and recruited participating centres. NDAB, NVDV, KAH, OJDV, FUSMR, and TJMVDC, supervised conduct of trial, screening of records, and collected data. All authors approved the final version of the manuscript. Trial collaborators participated in the screening of potential participants, and collecting trial data.

\section{Competing interests}

The authors declare no conflict of interest.

\section{Consent for publication}

Not Applicable.

\section{Ethics approval and consent to participate}

The study was approved by the Medical Research Ethics Committees in the six participating hospitals. The study was performed in accordance with the Declaration of Helsinki and all participants gave written informed consent.

\section{Author details}

'Department of Public Health, Erasmus MC, University Medical Center Rotterdam, PO Box 20403000, CA, Rotterdam, The Netherlands. ${ }^{2}$ Section of
Geriatric Medicine, Department of Internal Medicine, Erasmus MC, University Medical Center Rotterdam, Rotterdam, The Netherlands. ${ }^{3}$ Trauma Research Unit Department of Surgery, Erasmus MC, University Medical Center Rotterdam, Rotterdam, The Netherlands. ${ }^{4}$ Department of Emergency Medicine, Erasmus MC, University Medical Center Rotterdam, Rotterdam, The Netherlands. ${ }^{5}$ Department of Internal Medicine, VU University Medical Center, Amsterdam, The Netherlands.

Received: 1 July 2016 Accepted: 25 October 2016

Published online: 04 November 2016

\section{References}

1. Boonen S, Autier P, Barette M, Vanderschueren D, Lips P, Haentjens P. Functional outcome and quality of life following hip fracture in elderly women: a prospective controlled study. Osteoporos Int. 2004:15(2):87-94.

2. Close JC, Lord SR, Antonova EJ, Martin M, Lensberg B, Taylor M, Hallen J, Kelly A. Older people presenting to the emergency department after a fall: a population with substantial recurrent healthcare use. Emerg Med J. 2012:29(9):742-7.

3. Hartholt KA, van Beeck EF, Polinder S, van der Velde N, van Lieshout EM, Panneman MJ, van der Cammen TJ, Patka P. Societal consequences of falls in the older population: injuries, healthcare costs, and long-term reduced quality of life. J Trauma. 2010;71(3):748-53.

4. Randell AG, Nguyen TV, Bhalerao N, Silverman SL, Sambrook PN, Eisman JA. Deterioration in quality of life following hip fracture: a prospective study. Osteoporos Int. 2000;11(5):460-6.

5. Tinetti ME, Baker DI, McAvay G, Claus EB, Garrett P, Gottschalk M, Koch ML, Trainor K, Horwitz RI. A multifactorial intervention to reduce the risk of falling among elderly people living in the community. $\mathrm{N}$ Engl J Med. 1994:331(13):821-7.

6. Boye ND, Mattace-Raso FU, Van der Velde N, Van Lieshout EM, De Vries OJ, Hartholt KA, Kerver AJ, Bruijninckx MM, Van der Cammen TJ, Patka P, et al. Circumstances leading to injurious falls in older men and women in the Netherlands. Injury. 2014;45(8):1224-30.

7. Hartholt KA, Van Lieshout EM, Polinder S, Panneman MJ, Van der Cammen TJ, Patka P. Rapid increase in hospitalizations resulting from fall-related traumatic head injury in older adults in The Netherlands 1986-2008. J Neurotrauma. 2011;28(5):739-44.

8. Stevens JA, Corso PS, Finkelstein EA, Miller TR. The costs of fatal and nonfatal falls among older adults. Inj Prev. 2006;12(5):290-5.

9. Hartholt K, Polinder S, Van der Cammen T, Panneman M, Van der Velde N, Van Lieshout E, Patka P, Van Beeck E. Costs of falls in an ageing population: a nationwide study from the Netherlands (2007-2009). Injury. 2012;43(7): 1199-203.

10. Polinder S, Haagsma J, Panneman M, Scholten A, Brugmans M, Van Beeck E. The economic burden of injury: Health care and productivity costs of injuries in the Netherlands. Accid Anal Prev. 2016:93:92-100.

11. AGS/BGS. Summary of the Updated American Geriatrics Society/British Geriatrics Society clinical practice guideline for prevention of falls in older persons. J Am Geriatr Soc. 2010;59(1):148-57.

12. AGS/BGS/AAOS. Guideline for the prevention of falls in older persons. American Geriatrics Society, British Geriatrics Society, and American Academy of Orthopaedic Surgeons Panel on Falls Prevention. J Am Geriatr Soc. 2001;49(5):664-72

13. Tinetti ME, Speechley M, Ginter SF. Risk factors for falls among elderly persons living in the community. N Engl J Med. 1988;319(26):1701-7.

14. Campbell AJ, Robertson MC, Gardner MM, Norton RN, Buchner DM. Psychotropic medication withdrawal and a home-based exercise program to prevent falls: a randomized, controlled trial. J Am Geriatr Soc. 1999;47(7):850-3.

15. Campbell AJ, Robertson MC, Gardner MM, Norton RN, Buchner DM. Falls prevention over 2 years: a randomized controlled trial in women 80 years and older. Age Ageing. 1999;28(6):513-8.

16. Close J, Ellis M, Hooper R, Glucksman E, Jackson S, Swift C. Prevention of falls in the elderly trial (PROFET): a randomised controlled trial. Lancet 1999:353(9147):93-7.

17. Davison J, Bond J, Dawson P, Steen IN, Kenny RA. Patients with recurrent falls attending Accident \& Emergency benefit from multifactorial intervention-a randomised controlled trial. Age Ageing. 2005;34(2):162-8. 
18. de Vries OJ, Peeters GM, Elders PJ, Muller M, Knol DL, Danner SA, Bouter LM, Lips P. Multifactorial intervention to reduce falls in older people at high risk of recurrent falls: a randomized controlled trial. Arch Intern Med. 2011;170(13):1110-7.

19. Jensen J, Lundin-Olsson L, Nyberg L, Gustafson Y. Fall and injury prevention in older people living in residential care facilities. A cluster randomized trial. Ann Intern Med. 2002;136(10):733-41.

20. Mahoney JE, Shea TA, Przybelski R, Jaros L, Gangnon R, Cech S, Schwalbe A. Kenosha County falls prevention study: a randomized, controlled trial of an intermediate-intensity, community-based multifactorial falls intervention. J Am Geriatr Soc. 2007;55(4):489-98.

21. Province MA, Hadley EC, Hornbrook MC, Lipsitz LA, Miller JP, Mulrow CD, Ory MG, Sattin RW, Tinetti ME, Wolf SL. The effects of exercise on falls in elderly patients. A preplanned meta-analysis of the FICSIT trials. Frailty and injuries: cooperative studies of intervention techniques. JAMA. 1995;273(17):1341-7.

22. Spice CL, Morotti W, George S, Dent TH, Rose J, Harris S, Gordon CJ. The Winchester falls project: a randomised controlled trial of secondary prevention of falls in older people. Age Ageing. 2009;38(1):33-40.

23. Lamb SE, Jorstad-Stein EC, Hauer K, Becker C. Development of a common outcome data set for fall injury prevention trials: the Prevention of Falls Network Europe consensus. J Am Geriatr Soc. 2005;53(9):1618-22.

24. Clemson L, Cumming RG, Kendig H, Swann M, Heard R, Taylor K. The effectiveness of a community-based program for reducing the incidence of falls in the elderly: a randomized trial. J Am Geriatr Soc. 2004;52(9):1487-94.

25. Elley CR, Robertson MC, Garrett S, Kerse NM, McKinlay E, Lawton B, Moriarty $\mathrm{H}$, Moyes SA, Campbell AJ. Effectiveness of a falls-and-fracture nurse coordinator to reduce falls: a randomized, controlled trial of at-risk older adults. J Am Geriatr Soc. 2008;56(8):1383-9.

26. Lin MR, Wolf SL, Hwang HF, Gong SY, Chen CY. A randomized, controlled trial of fall prevention programs and quality of life in older fallers. J Am Geriatr Soc. 2007;55(4):499-506

27. Vaapio S, Salminen M, Vahlberg T, Sjosten N, Isoaho R, Aarnio P, Kivela SL. Effects of risk-based multifactorial fall prevention on health-related quality of life among the community-dwelling aged: a randomized controlled trial. Health Qual Life Outcomes. 2007;5:20.

28. Thomas S, Mackintosh S, Halbert J. Does the 'Otago exercise programme' reduce mortality and falls in older adults?: a systematic review and metaanalysis. Age Ageing. 2010;39(6):681-7.

29. Juarez D, Goo R, Tokumaru S, Sentell T, Davis J, Mau M. Impact of sustained hemoglobin a1c control on health care costs among patients with diabetes in Hawaii. Value Health. 2012;15(4):A177-8.

30. Rizzo JA, Baker DI, McAvay G, Tinetti ME. The cost-effectiveness of a multifactorial targeted prevention program for falls among community elderly persons. Med Care. 1996;34(9):954-69.

31. Hartholt KA, Becker ML, van der Cammen TJ. Drug-induced falls in older persons: is there a role for therapeutic drug monitoring? Ther Adv Drug Saf. 2016;7(2):39-42

32. Leipzig RM, Cumming RG, Tinetti ME. Drugs and falls in older people: a systematic review and meta-analysis: II. Cardiac and analgesic drugs. J Am Geriatr Soc. 1999;47(1):40-50.

33. Leipzig RM, Cumming RG, Tinetti ME. Drugs and falls in older people: a systematic review and meta-analysis: I. Psychotropic drugs. J Am Geriatr Soc. 1999;47(1):30-9.

34. Sterke CS, Ziere G, van Beeck EF, Looman CW, van der Cammen TJ. Doseresponse relationship between selective serotonin re-uptake inhibitors and injurious falls: a study in nursing home residents with dementia. Br J Clin Pharmacol. 2012;73(5):812-20.

35. Woolcott JC, Richardson KJ, Wiens MO, Patel B, Marin J, Khan KM, Marra CA. Meta-analysis of the impact of 9 medication classes on falls in elderly persons. Arch Intern Med. 2009;169(21):1952-60.

36. van der Velde N, Meerding WJ, Looman CW, Pols HA, van der Cammen TJ. Cost effectiveness of withdrawal of fall-risk-increasing drugs in geriatric outpatients. Drugs Aging. 2008;25(6):521-9.

37. van der Velde N, Stricker BH, Pols HA, van der Cammen TJ. Risk of falls after withdrawal of fall-risk-increasing drugs: a prospective cohort study. Br J Clin Pharmacol. 2007:63(2):232-7.

38. Hartholt KA, Boyé NDA, Van der Velde N, Van Lieshout EMM, Polinder S, De Vries OJ, Kerver AJ, Ziere G, Bruijninckx MM, De Vries MR, et al. [Cost] effectiveness of withdrawal of fall-risk increasing drugs versus conservative treatment in older fallers: design of a multicenter randomized controlled trial (IMPROveFALL-study). BMC Geriatr. 2011;11:48.
39. Folstein MF, Folstein SE, McHugh PR. "Mini-mental state". A practical method for grading the cognitive state of patients for the clinician. J Psychiatr Res. 1975;12(3):189-98.

40. KIWG. The prevention of falls in later life. A report of the Kellogg International Work Group on the Prevention of Falls by the Elderly. Dan Med Bull. 1987;34 Suppl 4:1-24.

41. Hakkaart-van Roijen L, Tan SS, Bouwmans CAM. Handleiding voor kostenonderzoek. In: College voor zorgverzekeringen. 2010.

42. Farmacotherapeutisch Kompas. Diemen, Netherlands: College voor zorgverzekeringen; 2012.

43. Brooks R. EuroQol: the current state of play. Health Policy. 1996;37(1):53-72.

44. Gandek B, Ware JE, Aaronson NK, Apolone G, Bjorner JB, Brazier JE, Bullinger M, Kaasa S, Leplege A, Prieto L, et al. Cross-validation of item selection and scoring for the SF-12 Health Survey in nine countries: results from the IQOLA Project. International Quality of Life Assessment. J Clin Epidemiol. 1998;51(11):1171-8.

45. Van Beeck EF, Larsen CF, Lyons RA, Meerding WJ, Mulder S, Essink-Bot ML. Guidelines for the conduction of follow-up studies measuring injury-related disability. J Trauma. 2007;62(2):534-50.

46. Dolan P. Modeling valuations for EuroQol health states. Med Care. 1997; 35(11):1095-108.

47. Oostenbrink JB, Koopmanschap MA, Rutten FF. Standardisation of costs: the Dutch Manual for Costing in economic evaluations. Pharmacoeconomics. 2002;20(7):443-54.

48. Boye NDA, Van der Velde N, De Vries OJ, Van Lieshout EMM, Hartholt KA, Mattace-Raso FUS, Lips P, Patka P, Van Beeck EF, Van der Cammen TJM, et al. Effectiveness of Medication Withdrawal in Older Fallers: Results from the Improving Medication Prescribing to reduce Risk Of FALLs (IMPROveFALL) Trial. Age Ageing. 2016 (in press).

49. Campbell AJ, Robertson MC, La Grow SJ, Kerse NM, Sanderson GF, Jacobs RJ, Sharp DM, Hale LA. Randomised controlled trial of prevention of falls in people aged $>$ or $=75$ with severe visual impairment: the VIP trial. BMJ. 2005;331(7520):817.

50. Church J, Goodall S, Norman R, Haas M. An economic evaluation of community and residential aged care falls prevention strategies in NSW. N S W Public Health Bull. 2011;22(3-4):60-8.

51. Davis JC, Marra CA, Robertson MC, Khan KM, Najafzadeh M, Ashe MC, LiuAmbrose T. Economic evaluation of dose-response resistance training in older women: a cost-effectiveness and cost-utility analysis. Osteoporos Int. 2011;22(5):1355-66.

52. Heinrich S, Rapp K, Stuhldreher N, Rissmann U, Becker C, Konig HH. Costeffectiveness of a multifactorial fall prevention program in nursing homes. Osteoporos Int. 2013;24(4):1215-23.

53. Hendriks MR, Evers SM, Bleijlevens MH, van Haastregt JC, Crebolder HF, van Eijk JT. Cost-effectiveness of a multidisciplinary fall prevention program in community-dwelling elderly people: a randomized controlled trial (ISRCTN 64716113). Int J Technol Assess Health Care. 2008;24(2):193-202.

54. Irvine L, Conroy SP, Sach T, Gladman JR, Harwood RH, Kendrick D, Coupland C, Drummond A, Barton G, Masud T. Cost-effectiveness of a day hospital falls prevention programme for screened community-dwelling older people at high risk of falls. Age Ageing. 2010;39(6):710-6.

55. Jenkyn KB, Hoch JS, Speechley M. How much are we willing to pay to prevent a fall? Cost-effectiveness of a multifactorial falls prevention program for community-dwelling older adults. Can J Aging. 2012;31(2):121-37.

56. Peeters GM, Heymans MW, de Vries OJ, Bouter LM, Lips P, van Tulder MW. Multifactorial evaluation and treatment of persons with a high risk of recurrent falling was not cost-effective. Osteoporos Int. 2011;22(7):2187-96.

57. Robertson MC, Devlin N, Gardner MM, Campbell AJ. Effectiveness and economic evaluation of a nurse delivered home exercise programme to prevent falls. 1: Randomised controlled trial. BMJ. 2001;322(7288):697-701.

58. Sach TH, Logan PA, Coupland CA, Gladman JR, Sahota O, Stoner-Hobbs V, Robertson K, Tomlinson V, Ward M, Avery AJ. Community falls prevention for people who call an emergency ambulance after a fall: an economic evaluation alongside a randomised controlled trial. Age Ageing. 2012:41(5):635-41.

59. Pit SW, Byles JE, Henry DA, Holt L, Hansen V, Bowman DA. A quality use of medicines program for general practitioners and older people: a cluster randomised controlled trial. Med J Aust. 2007;187:23-30.

60. Elskamp AB, Hartholt KA, Patka P, van Beeck EF, van der Cammen TJ. Why older people refuse to participate in falls prevention trials: a qualitative study. Exp Gerontol. 2012;47(4):342-5. 